\title{
Contrast-induced nephropathy
}

\section{Mark O. Baerlocher MD, Murray Asch MD, Andy Myers MD}

Previously published at www.cmaj.ca

\section{Contrast-induced nephropathy is a common cause of hospital-acquired renal failure}

Contrast-induced nephropathy is defined as a serum creatinine level that increases by at least $25 \%$ or is $44.2 \mu \mathrm{mol} / \mathrm{L}$ greater than baseline within three days of receiving contrast medium intravascularly in the absence of another cause. ${ }^{1}$ Contrastinduced nephropathy is usually selflimiting; at worst, it can make the patient permanently dependent on hemodialysis or can result in death.

\author{
Main risk factors are renal dys- \\ function and diabetes (particularly \\ in the presence of chronic renal \\ disease) \\ The possibility of renal dysfunction \\ should be considered in a patient \\ with one or more of the following \\ characteristics: ${ }^{2}$ \\ - dehydration \\ - increased age \\ - use of nephrotoxic drugs (e.g., \\ nonsteroidal anti-inflammatory \\ drugs, loop diuretics, aminogly- \\ cosides, chemotherapy) \\ - heart failure \\ - cirrhosis \\ - sepsis
}

\section{Assess renal function in a patient with risk factors}

A patient with diabetes or possible renal dysfunction should have his or her renal function assessed before undergoing contrast-enhanced imaging. The estimated glomerular filtration rate is the preferred measure. The serum creatinine level may not be an accurate measure in elderly and very frail patients. An estimated glomerular filtration rate of 30 $59 \mathrm{~mL} / \mathrm{min}$ per $1.73 \mathrm{~m}^{2}$ indicates moderate renal dysfunction. An estimated rate of less than $30 \mathrm{~mL} / \mathrm{min}$ per $1.73 \mathrm{~m}^{2}$ indicates severe renal dysfunction. ${ }^{3}$

\section{Consider alternative imaging tests}

In a patient with moderate or severe renal dysfunction, alternative imaging tests may yield the same information without the risks. Other options include computed tomography without contrast medium, ultrasonography and magnetic resonance imaging.

\section{REFERENCES}

1. Morcos SK, Thomsen HS, Webb JA. Contrastmedia-induced nephrotoxicity: a consensus report. Contrast Media Safety Committee, European Society of Urogenital Radiology (ESUR). Eur Radiol 1999;9:1602-13.

2. Benko A, Fraser-Hill M, Magner P, et al. Canadian Association of Radiologists: consensus guidelines for the prevention of contrast-induced nephropathy. Can Assoc Radiol J 2007;58:79-87.

3. K/DOQI clinical practice guidelines for chronic kidney disease: evaluation, classification, and stratification. Am J Kidney Dis 2002;39(Suppl 1):S1-266.

4. Thomsen HS, Morcos SK. Contrast media and the kidney: European Society of Urogenital Radiology (ESUR) guidelines. Br J Radiol 2003;76:513-8.

This article has been peer reviewed.

Competing interests: None declared.
From the Department of Medical Imaging (Baerlocher), University of Toronto, Toronto, Ont., and the Department of Radiology (Asch, Myers), Lakeridge Health Corporation, Oshawa, Ont. 